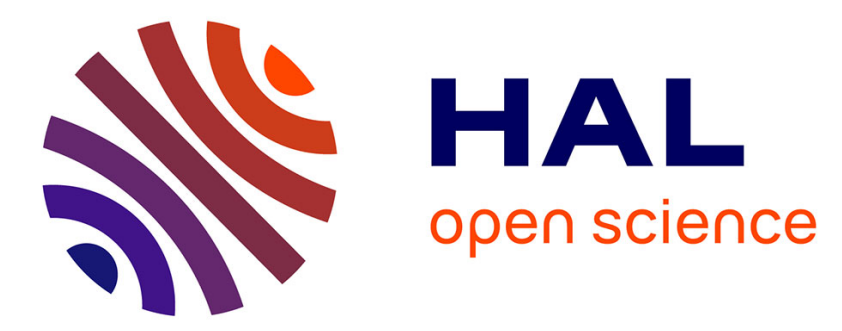

\title{
The effect of nitridation on the optical properties of InAs quantum dots grown on GaAs substrate by MBE
}

Syrine Naceur, Mohsen Choubani, Badreddine Smiri, Hassen Maaref, Guillaume Monier, Christine Robert-Goumet, Larbi Sfaxi, Bernard Gruzza, Ridha Mghaieth

\section{To cite this version:}

Syrine Naceur, Mohsen Choubani, Badreddine Smiri, Hassen Maaref, Guillaume Monier, et al.. The effect of nitridation on the optical properties of InAs quantum dots grown on GaAs substrate by MBE. Vacuum, 2020, 172, pp.109097. 10.1016/j.vacuum.2019.109097 . hal-03016506

\section{HAL Id: hal-03016506 https://hal.science/hal-03016506}

Submitted on 20 Nov 2020

HAL is a multi-disciplinary open access archive for the deposit and dissemination of scientific research documents, whether they are published or not. The documents may come from teaching and research institutions in France or abroad, or from public or private research centers.
L'archive ouverte pluridisciplinaire $\mathbf{H A L}$, est destinée au dépôt et à la diffusion de documents scientifiques de niveau recherche, publiés ou non, émanant des établissements d'enseignement et de recherche français ou étrangers, des laboratoires publics ou privés. 


\section{Journal Pre-proof}

The effect of nitridation on the optical properties of InAs quantum dots grown on GaAs substrate by MBE

S. Naceur, M. Choubani, B. Smiri, H. Maaref, G. Monier, C. Robert-Goumet, L. Sfaxi, B. Gruzza, R. Mghaieth

\section{VACUUM}

PII:

S0042-207X(19)32351-6

DOI:

https://doi.org/10.1016/j.vacuum.2019.109097

Reference: $\quad$ VAC 109097

To appear in: Vacuum

Received Date: 25 September 2019

Revised Date: 18 November 2019

Accepted Date: 19 November 2019

Please cite this article as: Naceur S, Choubani M, Smiri B, Maaref H, Monier G, Robert-Goumet C, Sfaxi L, Gruzza B, Mghaieth R, The effect of nitridation on the optical properties of InAs quantum dots grown on GaAs substrate by MBE, Vacuum, https://doi.org/10.1016/j.vacuum.2019.109097.

This is a PDF file of an article that has undergone enhancements after acceptance, such as the addition of a cover page and metadata, and formatting for readability, but it is not yet the definitive version of record. This version will undergo additional copyediting, typesetting and review before it is published in its final form, but we are providing this version to give early visibility of the article. Please note that, during the production process, errors may be discovered which could affect the content, and all legal disclaimers that apply to the journal pertain.

() 2019 Published by Elsevier Ltd. 


\title{
The effect of nitridation on the optical properties of InAs quantum dots grown on GaAs substrate by MBE
}

\author{
S. Naceur $^{a^{*}}$, M. Choubani ${ }^{\text {a }}$, B. Smiri ${ }^{a}$, H. Maaref ${ }^{a}$, G. Monier ${ }^{b}$, C. Robert-Goumet $^{\text {b }}$, L. Sfaxi ${ }^{\text {a }}$, \\ B. Gruzza ${ }^{\text {, }}$ R. Mghaieth ${ }^{a}$
}

${ }^{a}$ Laboratoire des Micro-optoélectroniques et Nanostructures, Université de Monastir, Faculté des sciences Monastir, Avenue de l'environnement 5019 Monastir, Tunisie.

${ }^{b}$ Institut Pascal, Université Clermont Auvergne, CNRS, SIGMA Clermont, F-63000 ClermontFerrand, France.

*Corresponding author: syna1991@gmail.com (syrine naceur)

\begin{abstract}
InAs/GaAs quantum dots (QDs) under their exposure to a nitrogen plasma were investigated using photoluminescence (PL) and X-Ray Photoelectron Spectroscopy (XPS) techniques. The motivation of this work is to study the effect of nitrogen in InAs QDs, and their role in the amelioration of optical properties. At low temperature, nitrogen addition causes a red-shift of the PL emission. This can be explained by reduction of quantum confinement. Powerdependent analysis of PL exhibit that the transition is about band-to-band intrinsic recombination which may be due to the formation of an $\ln \mathrm{AsN}$ thin layer at the interface of InAs QDs.

XPS is used to determine the species created at the surface. To follow QDs nitridation, we focused our attention on the N1s and In3d XPS spectra.

The temperature dependent PL measurements in the range 10-300 K for nitrided InAs QDs showed an S-shape in PL peak energy and contributed to an estimated value of exciton localization energy.

In addition, by increasing the time nitridation in InAs QDs, the emission wavelength increases further. Our results displayed a significant improvement of the crystalline quality and enhancement of the optical properties for InAs QDs grown after nitridation.
\end{abstract}

Keywords: Nitridation effect, InAs QDs, X-Ray Photoelectron Spectroscopy (XPS), Photoluminescence (PL), S-shape. 


\section{Introduction}

The growth of self-assembled InAs/GaAs quantum dots (QDs) has been studied extensively in recent years with particular prominence on optoelectronic devices [1,2] and for high performance and low-cost optical communication lasers $[3,4]$. However, a large InAs-GaAs lattice mismatch $(7 \%)$ induces an unwanted quantum dot band gap increase [5,6]. For this reason, in order to decrease this mismatch, nitrogen was added to InAs QDs [6].

The active regions of devices in semiconductor electronics have been regularly decreasing in recent years [7]. As a result, surfaces and interfaces have a larger influence on device characteristics. So, to eliminate the undesirable effect of the surface on device properties, the technique called 'nitridation' is being vigorously developed. In fact, the surface nitridation technology of III-V semi-conductors [8-10] has been a critical way for to extend the emitting wavelength [11,12]. Yang Zhao et al showed a significant improvement of the crystalline qualities and surface morphologies and enhancement of the electrical and optical properties for InN films after nitridation [13].

The photoluminescence study versus temperature provides useful information about the material, which is of considerable practical and theoretical interest. Nitridation of GaAs has been extensively studied mainly as the initial stage of GaN growth on GaAs wafers and as a method for the preparation of thick GaN layers [14-16]. To our knowledge, there have been very few reports on the nitridation of InAs.

This paper reports on the optical properties of InAs QDs grown on GaAs (100) substrate by solid source molecular beam epitaxy (MBE), which have been studied by X-Ray Photoelectron Spectroscopy (XPS) and PL experiments. We investigate the influence of nitridation on optical properties in InAs QDs. Also, we will discuss the influence of time nitridation in such structures.

\section{Experimental details}

Self-assembled InAs QDs were grown on GaAs substrate by MBE system with using Stranski -Krastanov (SK) process. Active N species were created in radio-frequency (rf) plasma using an electron cyclotron source from ultrapure $\mathrm{N}_{2}$ gas. The nitrogen partial pressure was $7-8.10^{-5}$ mbar. A $200 \mathrm{~nm}$ buffer layer of GaAs was grown at $580^{\circ} \mathrm{C}$. InAs deposition was performed at $500^{\circ} \mathrm{C}$. The deposition rate of InAs was $3 \mathrm{ML} / \mathrm{s}$, which was estimated from the reflection high energy electron diffraction (RHEED) oscillations. The transition from two-dimensional (2D) wetting layer to three-dimensional (3D) islands growth is determined from the change in the 
RHEED pattern (fig.1). The nominal deposition rate was $0.4 \AA /$ s. The studied samples $\mathrm{S} 0$ and S1 corresponding, respectively, to non-capped and capped GaAs layer. After growing InAs QDs, we performed atomic layer nitridation for two different durations of 1 and 3 hours (respectively for S2 and S3 samples).

The in-situ method based on X-Ray Spectroscopy (XPS) is developed in order to determine the nanostructure surface and chemical bonding [17] of a deposited InAs QDs on GaAs substrate after nitridation. XPS measurements were carried out in an UHV chamber equipped with an XPS system (dual anode Al-Mg X-ray source and hemispherical electron energy analyzer OMICRON EA125). The Mg Ka source (1253.6 eV) is separated from the analyzer by an angle of $55^{\circ}$ (almost the "magic angle": $\mathrm{L}=1$ ), constant pass energy of the analyzer equal to $20 \mathrm{eV}$ and Medium Magnification Mode was used for analysis. Considering the absence of adventitious carbon on the surface, binding energy was referenced to As3d5/2 peak of the GaAs substrate at $40.4 \mathrm{eV}$.

Photoluminescence (PL) was measured to characterize the nitrided QDs. The samples were excited by $514 \mathrm{~nm}$ line of $\mathrm{Ar}^{+}$ion laser. Spectral analysis of the luminescence measurements was dispersed using Jobin Yvin HRD1 monochromator and detected by a thermoelectrically cooled Si photodetector. The excitation density was fixed at $80 \mathrm{~W} / \mathrm{cm}^{2}$.

\section{Results and discussion}

Fig.2 shows the $10 \mathrm{~K}$ PL spectra of S0, S1 and S2 samples using $80 \mathrm{~mW}$ excitation in the range of 750-1100 $\mathrm{nm}$. In order to determine the exact peak energy of each samples, PL spectra were deconvoluted by using OriginPro analysis software with Gaussian function. Due to band-to-band recombination in GaAs, the A band appears in S0, S1 and S2 at the same energy around $1.44 \mathrm{eV}$ (gap of GaAs). The wide peak B appears at energies 1.24 and $1.22 \mathrm{eV}$ with a full width at half maximum (FWHM) of 157 and $140 \mathrm{meV}$, respectively, for S1 and S2 samples, which can be attributed to InAs quantum dots (QDs). The origin of the widening can be explained by the carrier scattering processes and quantum dot size variation [18]. Furthermore, we notice that the PL intensity of sample S2 is enhanced more than the intensity of sample S1 which can be explained by the decrease of non-radiative centers due to nitrogen incorporation effect $[\mathbf{1 9 , 2 0}]$. This phenomenon points out the relevance of incorporation of nitrogen in such structure would enhance the PL intensity. Based on the FWHM drop and intensity increase for sample $\mathrm{S} 2$ than that of sample $\mathrm{S} 1$, the crystalline quality is improved for 
sample S2. As a result, for sample S2 the enhancement of the crystalline quality is related to nitrogen incorporation. From another side, the presence of oxidation effect can be explained by the absence of GaAs cap layer in sample S0. In this case, the InAs QDs leading to surface roughness show a success of localization of carriers in InAs QDs, which is manifested by the appearance of low InAs QDs PL band.

The PL B-band displays a red shift with nitrogen addition as shown in fig.2c. The observed red shift of the QD PL by the nitridation is about $20 \mathrm{meV}$. Two possible explanations could be related to this behavior of PL peak for our samples: (i) the dislocations that were located in nitrided InAs QDs and (ii) the weaken of quantum confinement effect. In fact, according to the PL results as described above, the model which can be considered for our nitrided QDs is that a thin $\ln$ AsN layer [21] covers the InAs QDs. A similar conclusion was also reported by V. Sallet et al [11] attributed the low energy shoulder in nitrided InAs QDs to the reduction of quantum confinement.

In order to understand the nature of InAs peaks energies, the PL spectra at different optical excitation powers varying between 8 and $80 \mathrm{~mW}$ were measured as shown in fig.3 a and b. We notice that for sample S1 and S2, the PL intensity decreases with decreasing excitation power. By fitting the PL intensity drop, we obtained that the exponent $\mathrm{n}$ is at around of the unity and no saturation at higher excitation power [22] is detected (fig.4). This indicates that this PL transition is not ascribed to any impurity or defects, yet it is an intrinsic recombination (band-to-band) [22,23].

In addition, we observed a red shift in PL peak energy (P2) with the increase of power excitation for sample S2. All changes are illustrated with arrows in fig.3. This red shift produced at the higher excitation power comes from the band-bending effect $[\mathbf{2 3}, \mathbf{2 4}]$ induced by the spatial separation of electrons and holes at InAs/GaAs interface. This behavior is a fingerprint of a type-II radiative recombination [25]. For this reason, may be a new layer was produced at S2 sample caused by nitrogen incorporation. These results require more investigations.

Fig.5 $\mathbf{a}$ and $\mathbf{b}$ show the PL response of our structure at room temperature (300 K). For sample S1, a Gaussian fit of the PL spectra shows two peaks located at around $0.862 \mu \mathrm{m}(1.430 \mathrm{eV})$ for GaAs and 1.010 $\mu \mathrm{m}(1.228 \mathrm{eV})$ for InAs QDs. For sample S2, the two peaks are located at around $0.862 \mu \mathrm{m}(1.430 \mathrm{eV})$ and $1.014 \mu \mathrm{m}(1.223 \mathrm{eV})$ respectively for GaAs and InAs QDs. These results show the possibility of our structure application in optoelectronic devices such as solar cell [26]. 
To monitor the nitridation, in situ XPS measurements were performed. Using this technique, a large surface area is analyzed, gathering information from the InAs QDs and the GaAs substrate. Then we focused our attention on the N1s and In3d XPS spectra to specifically follow the nitridation of the QDs. Fig.6 show these spectra at $\mathrm{TOA}=0^{\circ}$ (take off angles) for samples S2 and S3. The N1s and In3d spectra are fitted using Gaussian peak after removing the background using the Shirley function. The In3d peaks of the samples S2 and S3, respectively shown in figs.6 a and c, exhibit two contributions ascribed to the In-As bonds at $444.0 \mathrm{eV}$ and to the In-N bonds at $444.5 \mathrm{eV}$ showing the nitridation of the QDs [27]. This last contribution can also be ascribed to In-O bonds but very few oxygen is detected after the nitridation on samples S2 and S3 (not shown here). The QDs nitridation is confirmed by the detection of the N1s peaks (figs.6b and d) which can be decomposed in three contributions, the main contribution is ascribed to the $\mathrm{In}-\mathrm{N}$ and Ga-N bonds at $396.5 \mathrm{eV}$ and the two other low contributions are due to a mixed compound In-(As,N) at $397.5 \mathrm{eV}$ and some interstitial nitrogen atoms at $402.8 \mathrm{eV}[\mathbf{2 8 , 2 9 ]}$. From these results, one can see that the QDs were successfully nitrided. Note that the In-N contribution detected in the In3d peak and the N1s signal of the sample S2 are lower than the ones for the sample S3 indicating a lower nitrogen quantity integrated in the QDs.

Now, in order to further confirm the effect of nitrogen incorporation, we increased the time of nitridation from 1 hour (Sample S2) to 3 hours (Sample S3) as mentioned in fig.7. As can be seen in this figure, the PL intensity of sample S2 is intense and narrower than that of sample S3. This phenomenon can be explained by the increase of nitrogen incorporation with the increase of nitridation time into the structure. We mention that longer duration of nitridation of InAs QDs could results drastically the deterioration of material quality, which may introduce scattering centers for residual carriers. Indeed, the PL peak energy shifts to low energies, which may be due to the increase of confinement effect with the increase of nitridation time [30]. Similar results have been reported by D.K. Shih et al [31].

Fig.8 $\mathbf{a}$ and $\mathbf{b}$ show the temperature dependent PL spectra with a fixed excitation of $80 \mathrm{~W} / \mathrm{cm}^{2}$ measured at temperatures varying from $10 \mathrm{~K}$ to $300 \mathrm{~K}$.

The temperature dependence of the PL peaks exhibits an S-shape phenomenon linked to the exciton localization. To prove our hypothesis, a detailed study as function of PL temperature is performed. The PL peak energy, the FWHM and the PL intensity are depicted in fig.9. We focus our study on the PL peak emission. The S-shaped form temperature dependence of emission energy, i.e. a red-blue-red shift with increasing temperature, is clearly shown. It 
exhibits an anomalous behavior between 10 and $300 \mathrm{~K}$ and can be divided into three temperature intervals. Firstly, at low temperature from 10 to $30 \mathrm{~K}$, the emission energy peak shows a red shift. This behavior is attributed to the recombination of photo-generated carriers trapped by localized states [32-34]. In fact, it is related to the modulated potential structure due to the non uniform insertion of nitrogen atoms. At the intermediate PL temperature between 30 and $90 \mathrm{~K}$, a significant increase of temperature thermalizes the localized carriers leading to the blue shift of the emission peak. Finally, at even higher temperature (90-300 K), the temperature dependence peak energy is mainly dominated by band-to-band transition and the peak energy will decrease as a thermal shrinkage of band gap energy [35].

Then, for PL linewidth (FWHM), the PL peak increases at high temperature and then drops above. This behavior can be clarified by transfer and thermalization of localized states. When the temperature increases up to the thermalization point, some of localized carriers occupy shallower localized states. This leads to linewidth increase. When approaching the high temperature, most localized carriers become progressively mobile [36].

Finally, the temperature dependence of PL peak intensity was investigated. At low temperature $(T<30 \mathrm{~K})$, PL intensity decreases. With increasing temperature, it is shown that the PL intensity of each sample increases first and then decreases drastically. At sufficiently high temperatures (beyond $60 \mathrm{~K}$ ), the mobility of the carriers increases, more carriers can reach to the localization potential within the potential minima where the PL peak is originated, which makes the spectral peak intensity increase. By increasing temperature further, the overall emission intensity gradually decreases. It indicates that the non-radiative recombination starts to dominate over the radiative recombination process [37].This should correspond to the thermal activated non-radiative recombination mechanism.

In fig.10 and in order to understand the mechanism of carrier thermal quenching in this system, we fit the experimental data of the integrated PL intensity ( $\mathrm{I}_{\mathrm{PL}}$ ) as a function of reciprocal temperature by using the Arrhenius equation [38]:

$$
I(T)=\frac{I_{0}}{1+A \exp \left(\frac{-E_{a}}{k_{b} T}\right)}
$$

Where $\mathrm{I}_{0}$ is the PL intensity at $10 \mathrm{~K}, \mathrm{~A}$ are the pre-factor including information about the escape rate of charge carriers, and $E_{a}$ are the thermal activation energies, which are the slope of Arrhenius plot and obtained by choosing the best fit. The value of $\mathrm{E}_{\mathrm{a}}$ gives us an idea about the depth of confining potential [37]. 
The activation energy values are 10 and $16 \mathrm{meV}$ respectively for sample S1 and Sample S2. It is obvious that the carriers need more thermal energy to overcome (i.e. larger depth of confining potential). It is interpreted as the presence of impurities and defects as non-radiative recombination centers in PL recombination. It is a competition between radiative and non radiative channels.

\section{Conclusion}

To sum up, we have studied self-assembled InAs QDs grown on GaAs substrate by molecular beam epitaxy (MBE) with and without nitrogen addition. PL measurement revealed that nitrogen has a significant effect on the optical properties. At low temperature, a red-shift of the InAs QDs transition has been observed with nitrogen addition. This can be explained by reduction of quantum confinement. The power-excitation density PL measurements confirm the type-II transition in nitrided sample, which may be due to the formation of a new layer at the interface of InAs QDs.

In situ XPS measurements after nitridation were performed. The QDs nitridation was confirmed by the detection of In3d and N1s XPS peaks. A detailed analysis of N1s XPS peaks reveals the presence of three contributions ascribed to In-N and Ga-N bonds, a mixed compound In-(As,N) and some interstitial nitrogen.

The enhancement of PL intensity of nitrided sample is caused by the defect states, which produced non-radiative centers. A systematic study of PL temperature dependence has shown an S-shape as a result of the competition process between localized and delocalized states at the interface. This phenomenon is more enhanced for the nitrided sample.

We show also that the long duration of nitridation of InAs QDs deteriorates drastically the material quality.

The InAs QDs grown after nitridation exhibited a significant improvement of optical properties. All these results show the possibility to integrate our structure in solar cell devices.

\section{Acknowledgements}

This work was supported by the University of Monastir, Laboratory of Micro-Optoelectronic and Nanostructures, Department of Physics, Faculty of Sciences Monastir, Tunisia and Clermont University, University of Blaise Pascal, Institute of Pascal, BP 10448, F-63000 Clermont-Ferrand, France and research Laboratory CNRS, UMR 6602, IP, F-63171 Aubière, France. 


\section{References}

[1] J. J. Dubowski, C. Ni`. Allen and S. Fafard, Appl. Phys. Lett., Vol. 77, No. 22 (2000).

[2] Phu Lam, Sabina Hatch, Jiang Wu, Mingchu Tang, Vitaliy G. Dorogan, Yuriy I. Mazur, Gregory J. Salamo, Iñigo Ramiro, Alwyn Seeds, Huiyun Liu,Nano Energy 6, 159-166(2014).

[3] D.A. Pryakhin, V.M. Danil'tsev, et al., Semiconductors 39,11-13(2005).

[4] R. Hamila, F. Saidi, P.H. Rodriguez, L. Auvray, Y. Monteil, H. Maaref, J. Alloys Compd. 506,10-13 (2010).

[5] M. Kikuno, T. Mori, H. Seki, K. Matsusita, T. Kita, and 0. Wada, International Conference on Indium Phosphide and Related Materials, (2005).

[6] T. Inoue, K. Matsusita, T. Kita, and 0. Wada, H. Mori, T. Sakata and H. Yasuda, Extended Abstracts of the 2005 International Conference on Solid State Devices and Materials, Kobe, pp.100-101 (2005).

[7] O. Ueda, J. Electrochem. Soc.: REVIEWS AND NEWS, Vol. 135, No. 1 (1988).

[8] Omer Salihoglu, Abdullah Muti, Kutlu Kutluer, Tunay Tansel, Rasit Turan, Coskun Kocabas, and Atilla Aydinli, J. Appl. Phys. 111, 074509 (2012).

[9] M. E. Jones, J. R. Shealy, and J. R. Engstrom, Appl. Phys. Lett. 67 (4), (1995).

[10] V. N. Bessolov and M. V. Lebedev, Semiconductors 32,11, (1998).

[11] V. Sallet, G. Patriarche, M.N. Merat-Combes, L. Largeau, O. Mauguin, and L. Travers, Journal of Crystal Growth 290, 80-86 (2006).

[12] Y. Y. Ke, M. H. Ya, Y. F. Chen, J. S. Wang, and H. H. Lin, Appl. Phys. Lett., Vol. 80, No. 19, (2002).

[13] Yang Zhao, Hui Wang, Guoguang Wu, Qiang Jing, Fubin Gao, Wancheng Li, Baolin Zhang, Guotong Du, , Vacuum 111, 15-18 (2015).

[14] H. Mehdi, G. Monier, P. E. Hoggan, L. Bideux, C. Robert-Goumet and V. G. Dubrovskii, Applied Surface ScienceVolume 427, Part A, 662-669 (2018).

[15] V. L. Berkovits, V. P. Ulin, M. Losurdo, P. Capezzuto, G. Bruno, G. Perna, and V. Capozz,Appl. Phys. Lett., 80, No. 20 (2002).

[16] M. Losurdo, P. Capezzuto, G. Bruno, and E. A. Irene, PHYSICAL REVIEW B,58,23, (1998).

[17] G. Greczynski, L. Hultman, Progress in Materials Science, 100591 (2019). 
[18] P. B. Joyce, T. J. Krzyzewski, G. R. Bell, T. S. Jones, S. Malik, D. Childs, and R. Murray, PHYSICAL REVIEW B VOLUME 62, NUMBER 16 (2000).

[19] T. Kitatani, K. Nakahara, M. Kondow, K. Uomi, and T. Tanaka, J. Cryst.Growth 209, 345 (2000).

[20] E. C. Le Ru, J. Fack, and R. Murray, PHYSICAL REVIEW B 67, 245318 (2003).

[21] Akio Yamamoto, Tomohiro Shin-ya, Toshimitsu Sugiura, Mitsugu Ohkubo, Akihiro Hashimoto, Journal of Crystal Growth 189/190 476-480 (1998).

[22] B. Smiri, I. Fraj, F. Saidi, R. Mghaieth, H. Maaref, Journal of Alloys and Compounds, 736, 29-34 (2018).

[23] Ying Wang, Xinzhi Sheng, Qinglin Guo, Xiaoli Li, Shufang Wang, Guangsheng Fu, Yuriy I. Mazur,Yurii Maidaniuk, Morgan E. Ware, Gregory J. Salamo, Baolai Liang and Diana L. Huffaker, Nanoscale Research Letters, 12:229 (2017).

[24] Maher Ezzedini, Tarek Hidouri, Mohamed Helmi Hadj Alouane, Amor Sayari, Elsayed Shalaan, Nicolas Chauvin, Larbi Sfaxi, Faouzi Saidi, Ahmed Al-Ghamdi, Catherine BruChevallier and Hassen Maaref, Nanoscale Research Letters, 12:450 (2017).

[25] K. Matsushita, T. Inoue, X. Shang, T, Mori, H. Seki, M. Kikuno, T, Kita and 0. Wada, H. Mori, T, Sakata, H. Yasuda, International Conference on Indium Phosphide and Related Materials, (2005).

[26] Lee, A. D., Qi Jiang, Mingchu Tang, Yunyan Zhang, Seeds, A. J., \& Huiyun Liu, IEEE Journal of Selected Topics in Quantum Electronics, 19(4), 1901107-1901107 (2013).

[27] E.J. Preisler, R.P. Strittmatter, T.C. McGill, and C.J. Hill, Applied Surface Science, 222, 6-12(2004).

[28] Q. X. Guo, M. Nishio, H. Ogawa, A. Wakahara and A. Yoshida, PHYSICAL REVIEW B, 58, 23 (1998).

[29] J-D. Hecht, F. Frost, T. Chassé, D. Hirsch, H. Neumann, A. Schindler, and F.Bigl, Applied Surface Science, 179, 196-202 (2001).

[30] F. Hatami, N. N. Ledentsov, M. Grundmann, J. Bo“hrer, F. Heinrichsdorff, M. Beer, D. Bimberg, S. S. Ruvimov, P. Werner, U. Gösele, J. Heydenreich, U. Richter,S. V. Ivanov, B. Ya. Meltser, P. S. Kop'ev, and Zh. I. Alferov, Appl. Phys. Lett. 67 (5), (1995).

[31] D.K. Shih, Jpn. J. Appl. Phys. 42, 375 (2003).

[32] S. A. Lourenço, I. F. L. Dias, J. L. Duarte, E. Laureto, V. M. Aquino, and J. C. Harmand, Brazilian Journal of Physics, vol. 37, no. 4, (2007). 
[33] Ling Min Kong, Jia Fa Cai , Zheng Yun Wu , Zheng Gong , Zhi Chuan Niu and Zhe Chuan Feng, Thin Solid Films 498, 188 - 192 (2006).

[34] Ya-Fen Wu, Jiunn Chyi Lee, Tzer-En Nee, and Jen-Cheng Wang, Journal of Luminescence 131, 1267-1271 (2011).

[35] W. Liu, D.G. Zhao, D.S. Jiang, P. Chen, Z.S. Liu, J.J. Zhu, M. Shi, D.M. Zhao, X. Li, J.P. Liu, S.M. Zhang, H. Wang, H. Yang, Journal of Alloys and Compounds, 625, 266270(2015).

[36] B. Smiri, T. Hidouri, F. Saidi, and H. Maaref, Applied Physics A, 125(2),134 (2019).

[37] I. Fraj, T. Hidouri, F. Saidi, L. Bouzaiene, L. Sfaxi, and H. Maaref, Superlattices and Microstructures, 17, 1-5 (2017).

[38] J. (Zi-Jian).Ju, B. Loitsch, T. Stettner, F. Schuster, M. Stutzmann, and G. Koblmüller, J.Appl.Phys.116, 053501(2014). 


\section{Figures}

Fig.1: RHEED images of a flat surface (2D) (a), a surface covered with islands (3D) (b), and a flat surface after deposition of GaAs capping layer (2D) (c).

Fig.2: (a), (b) and (c) Low temperature PL spectra of InAs/GaAs quantum dots for S0, S1 and S2 samples.

Fig.3: (a) and (b) PL spectra of samples $\mathrm{S} 1$ and $\mathrm{S} 2$ at $12 \mathrm{~K}$ at different excitation powers. This last vary from 0.8 to $80 \mathrm{~W} / \mathrm{cm}^{2}$.

Fig.4: Evolution of the PL peak energy versus excitation density for samples S1 and S2, respectively.

Fig.5: (a) and (b) Room temperature PL spectra respectively for samples S1 and S2. The dash lines are the Gaussian-fitting curves.

Fig.6: In3d and N1s photoelectron spectra for the nitridated samples S2 (a) and (b) and S3 (c) and $(\mathrm{d})$ respectively.

Fig.7: Variation of PL Intensity as function of nitridation time.

Fig.8: Temperature-dependent PL spectra respectively for samples S1 (a) and S2 (b).

Fig.9: Temperature dependence of PL peak energy (a), the full width at half maximum (FWHM) (b) and PL intensity (c) of samples S1, S2 and S3.

Fig.10 : (a) and (b) Evolution of the integrated intensity for the transition type I versus the inverse of the temperature (black scatters) and the corresponding linear fit (red line), for S1 and S2 samples, respectively. 
Fig.1:

(a)
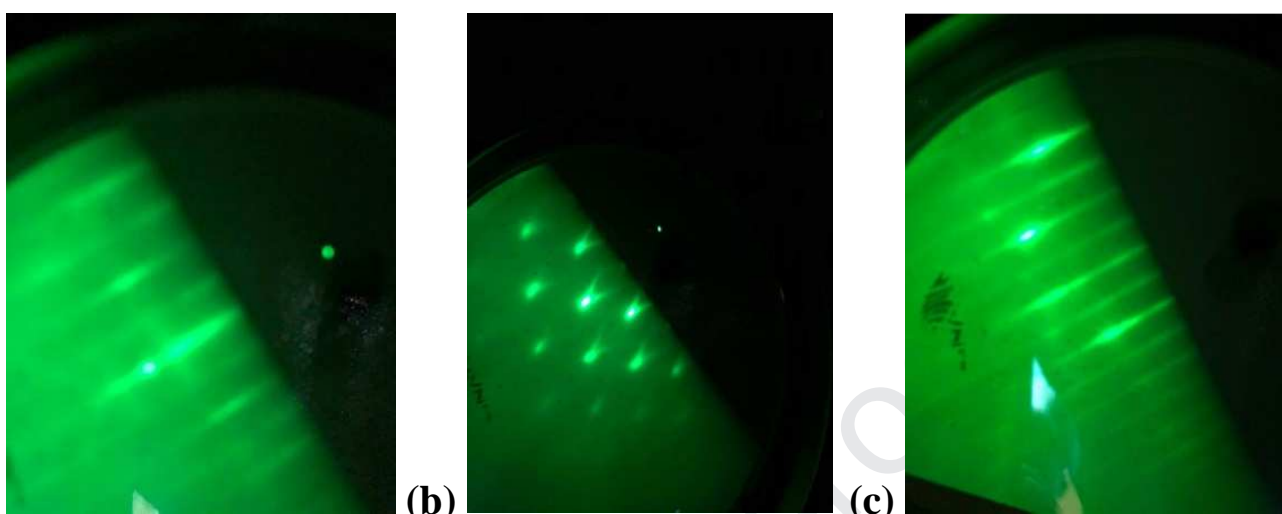

(b)

(c) 
Fig.2:

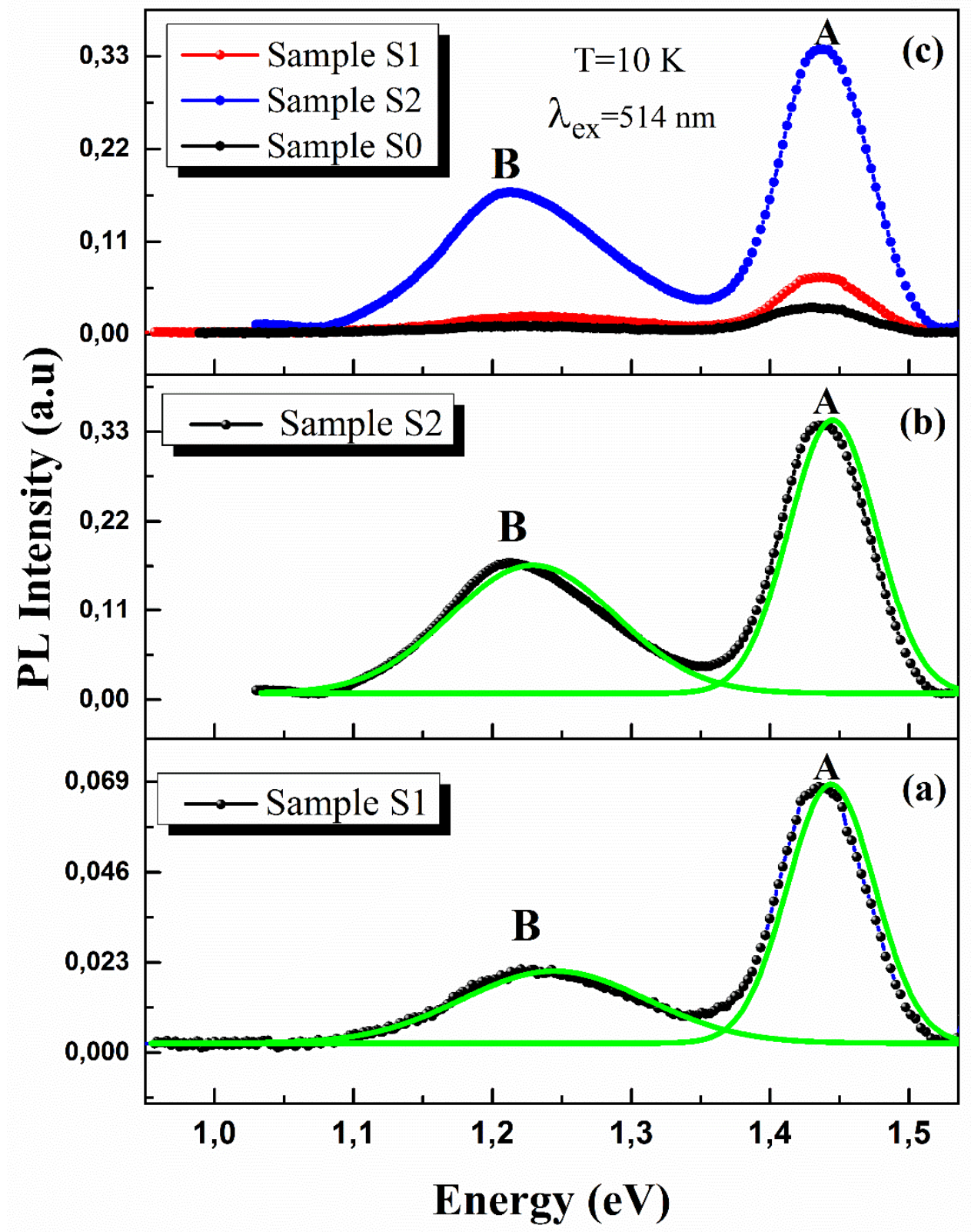


Fig.3:

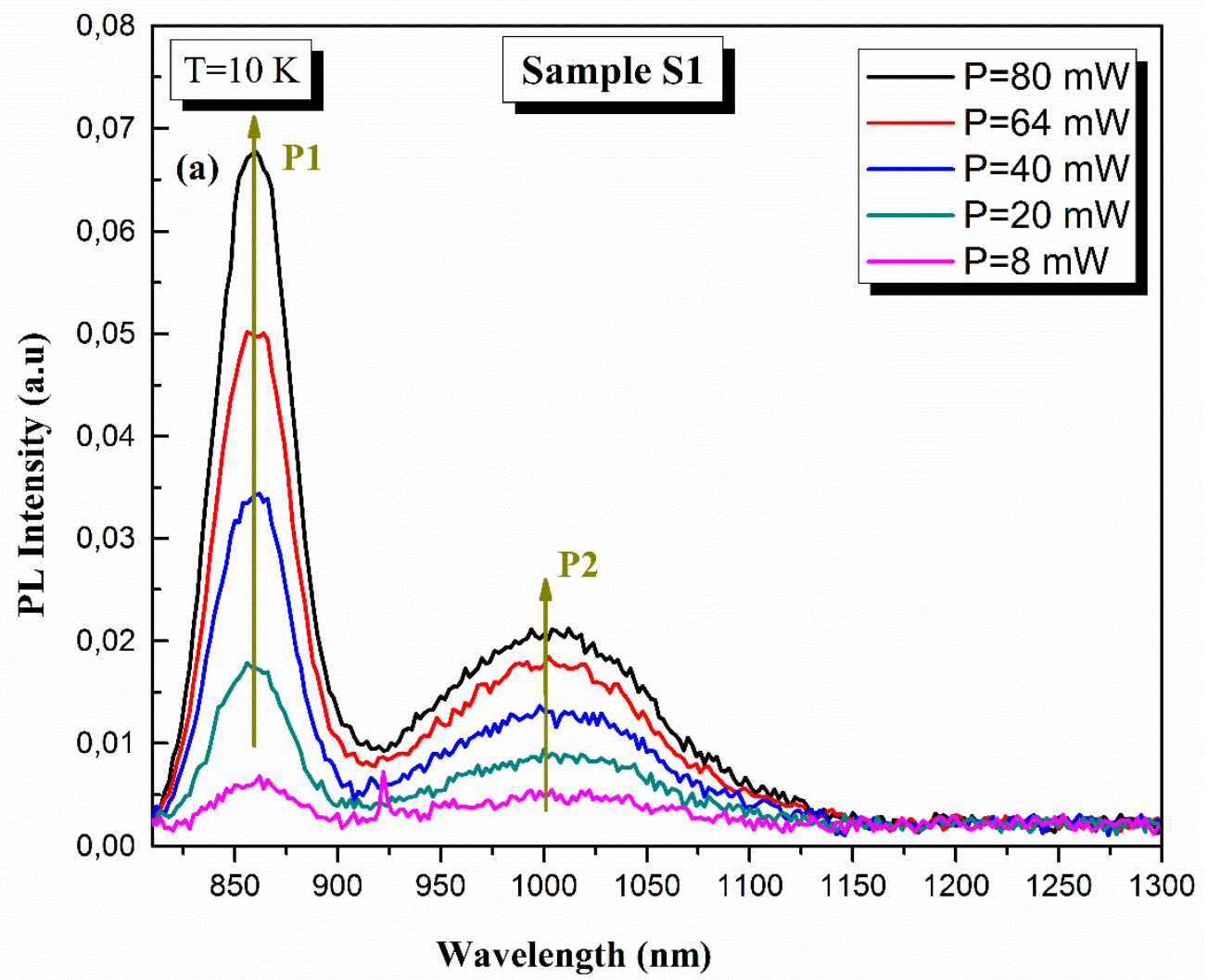




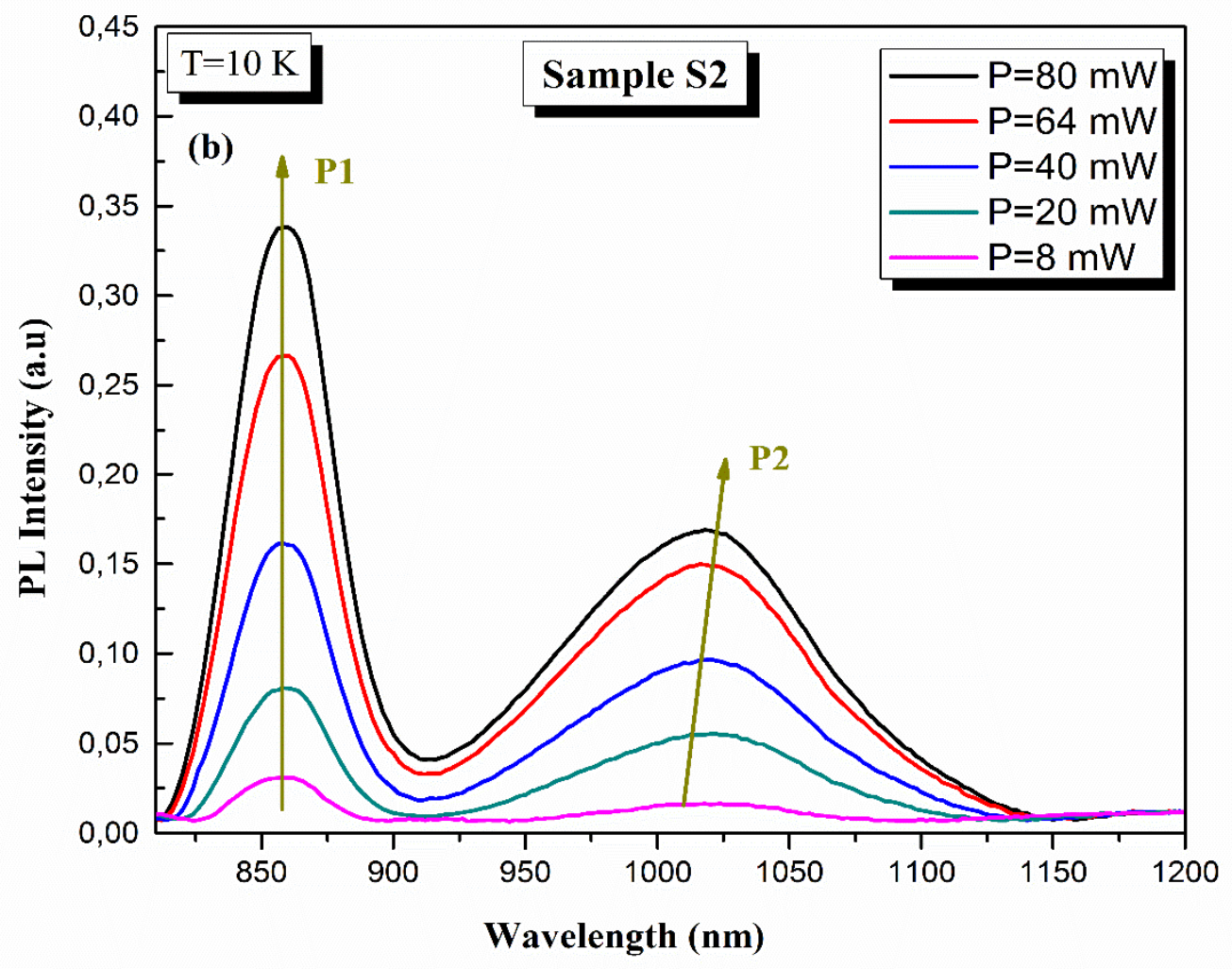

Fig.4:

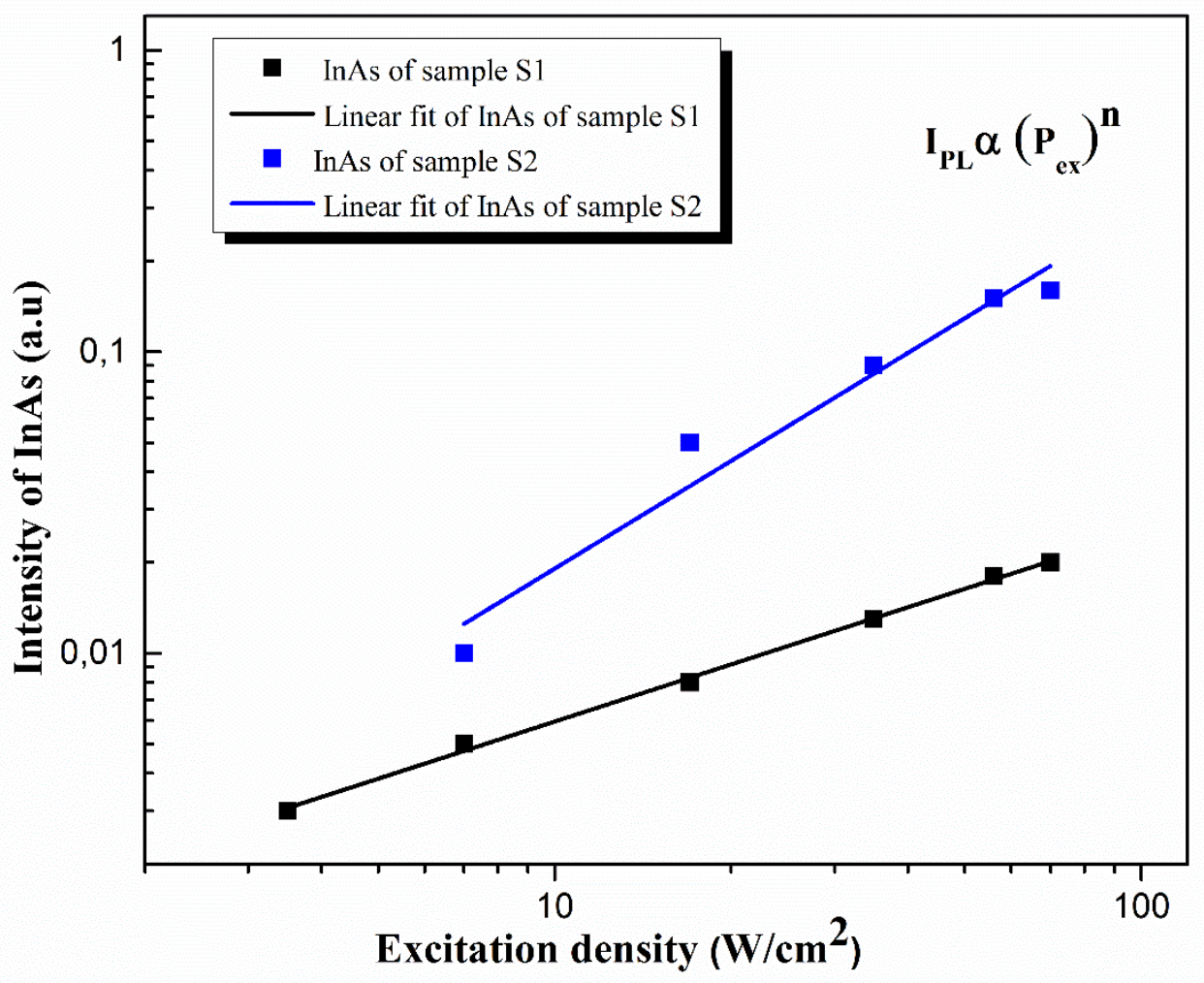


Fig.5:

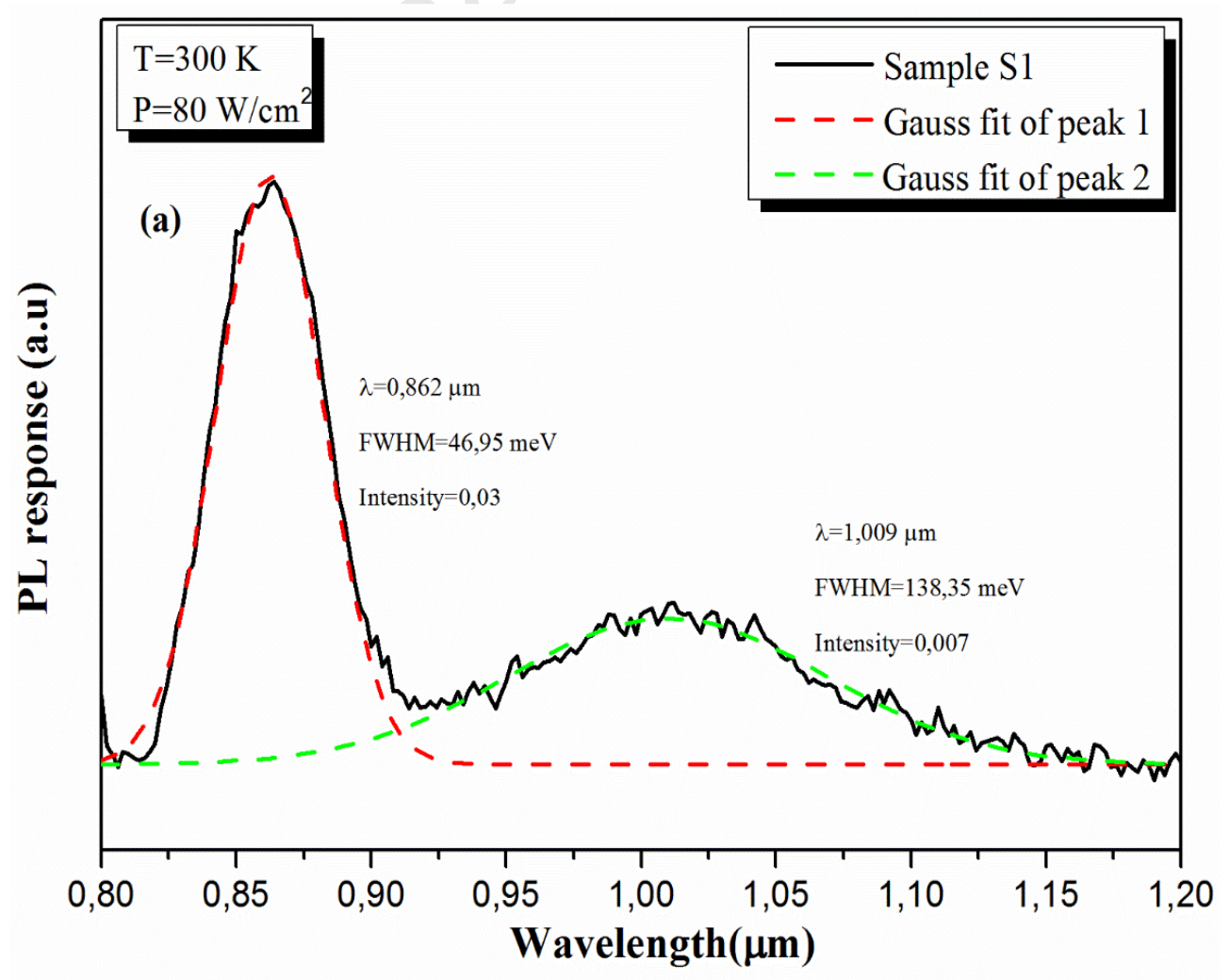




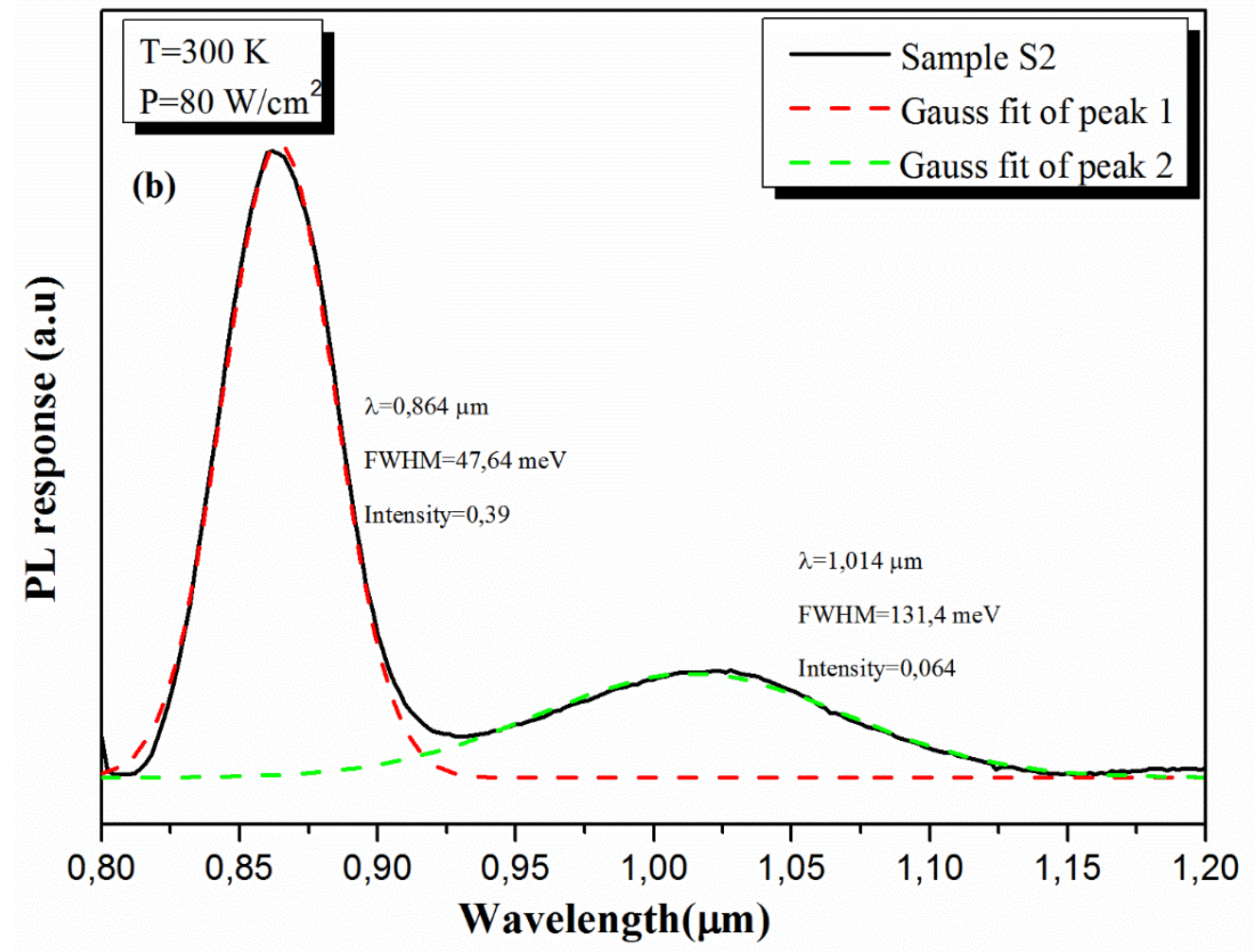

Fig.6:
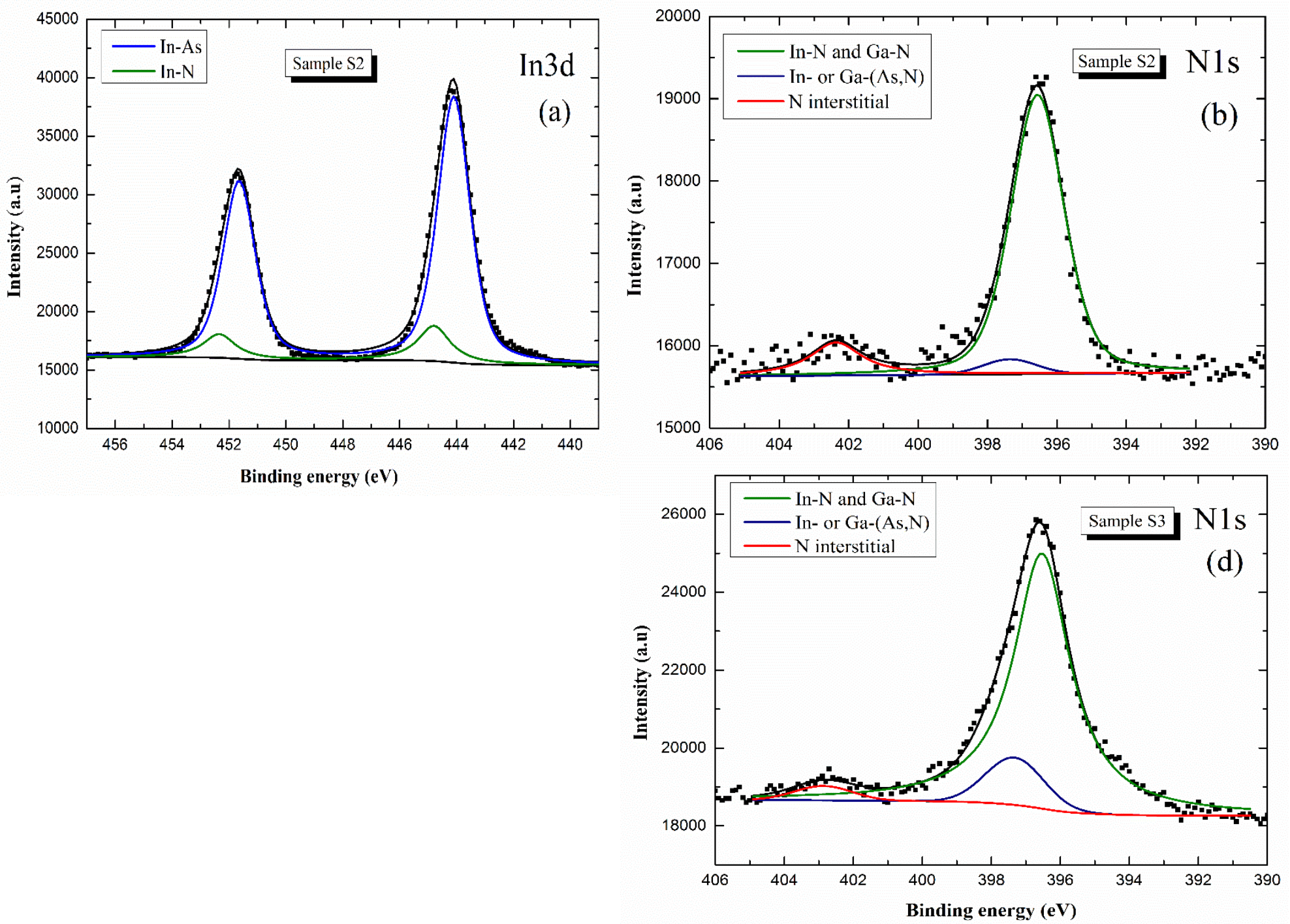
Fig.7:
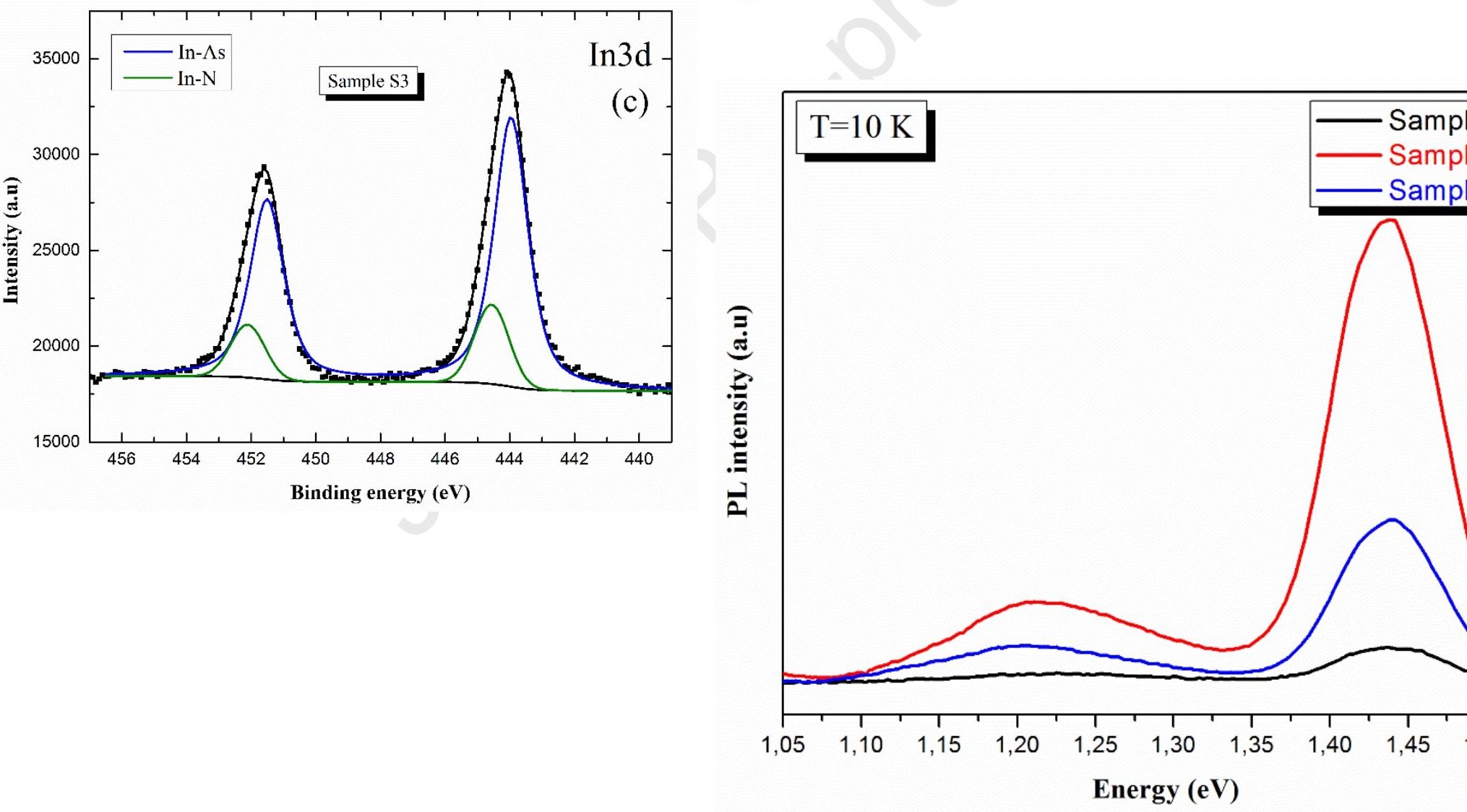
Fig.8

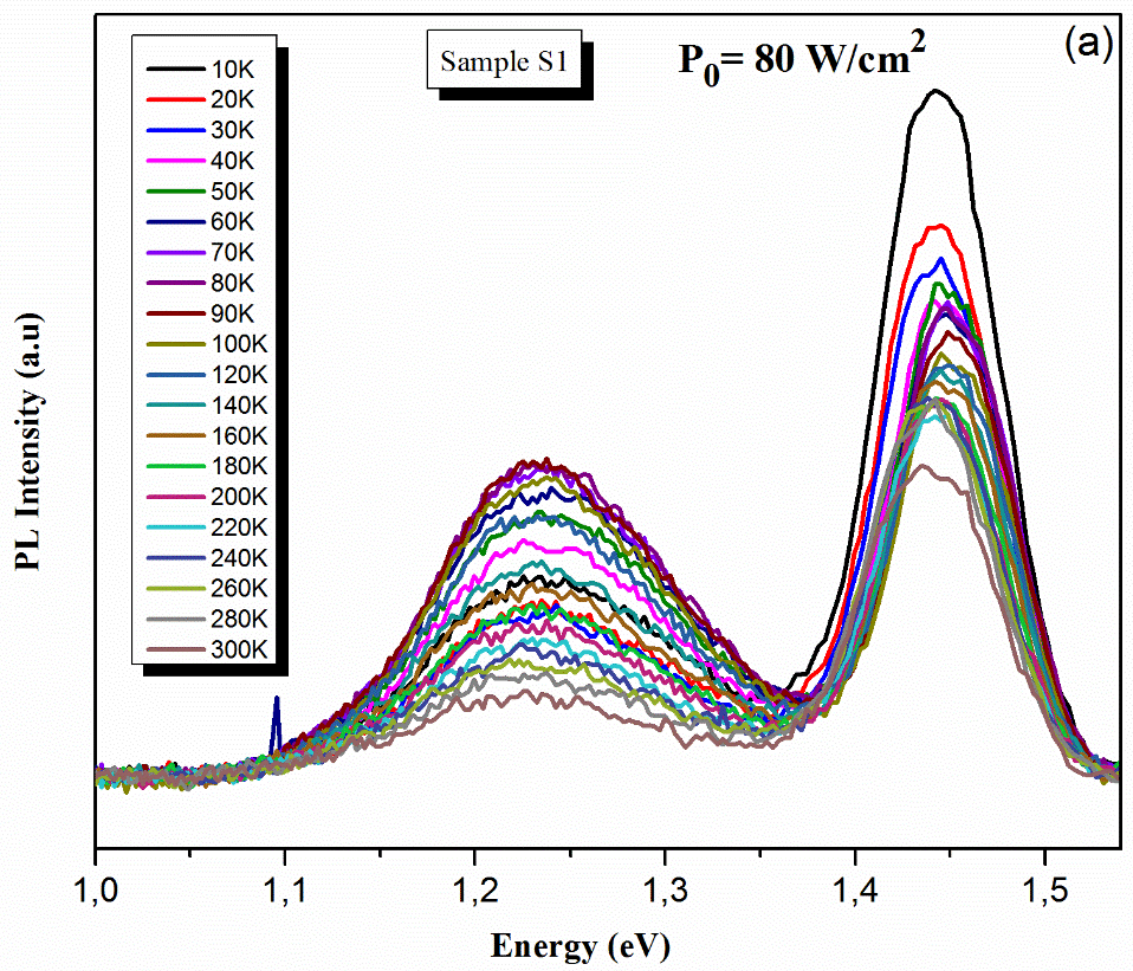




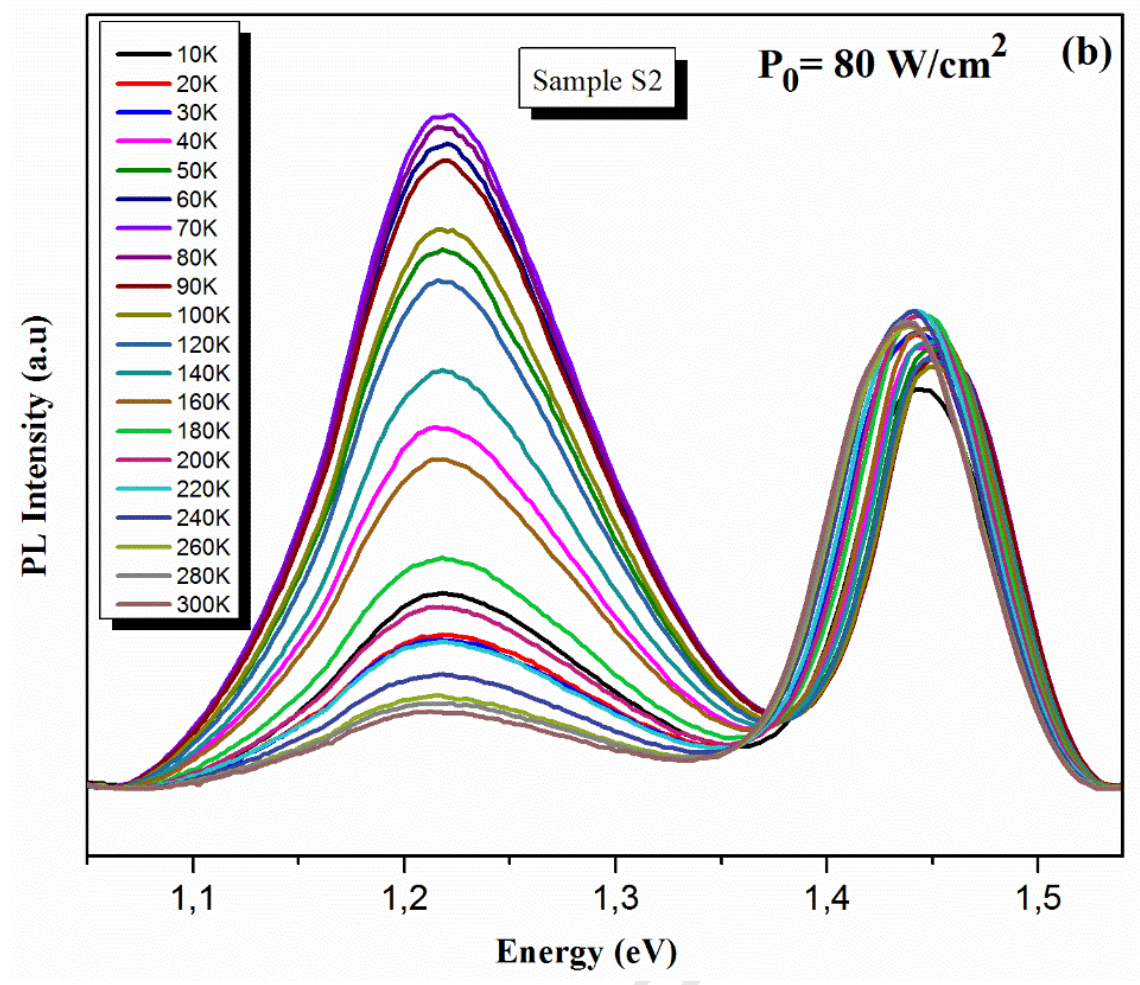

Fig.9:

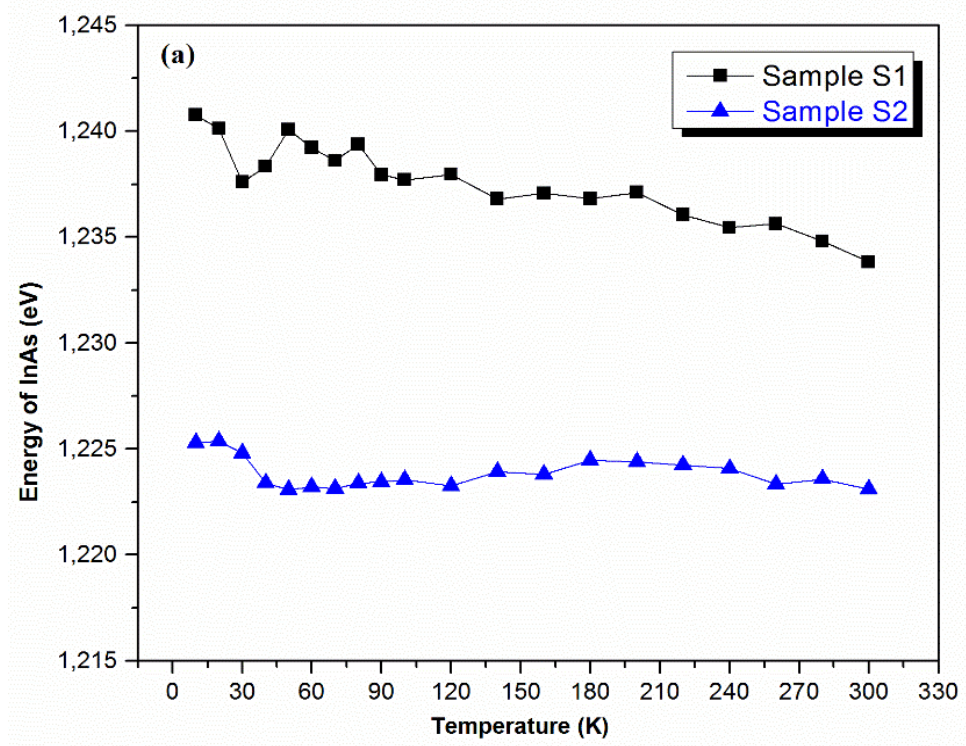



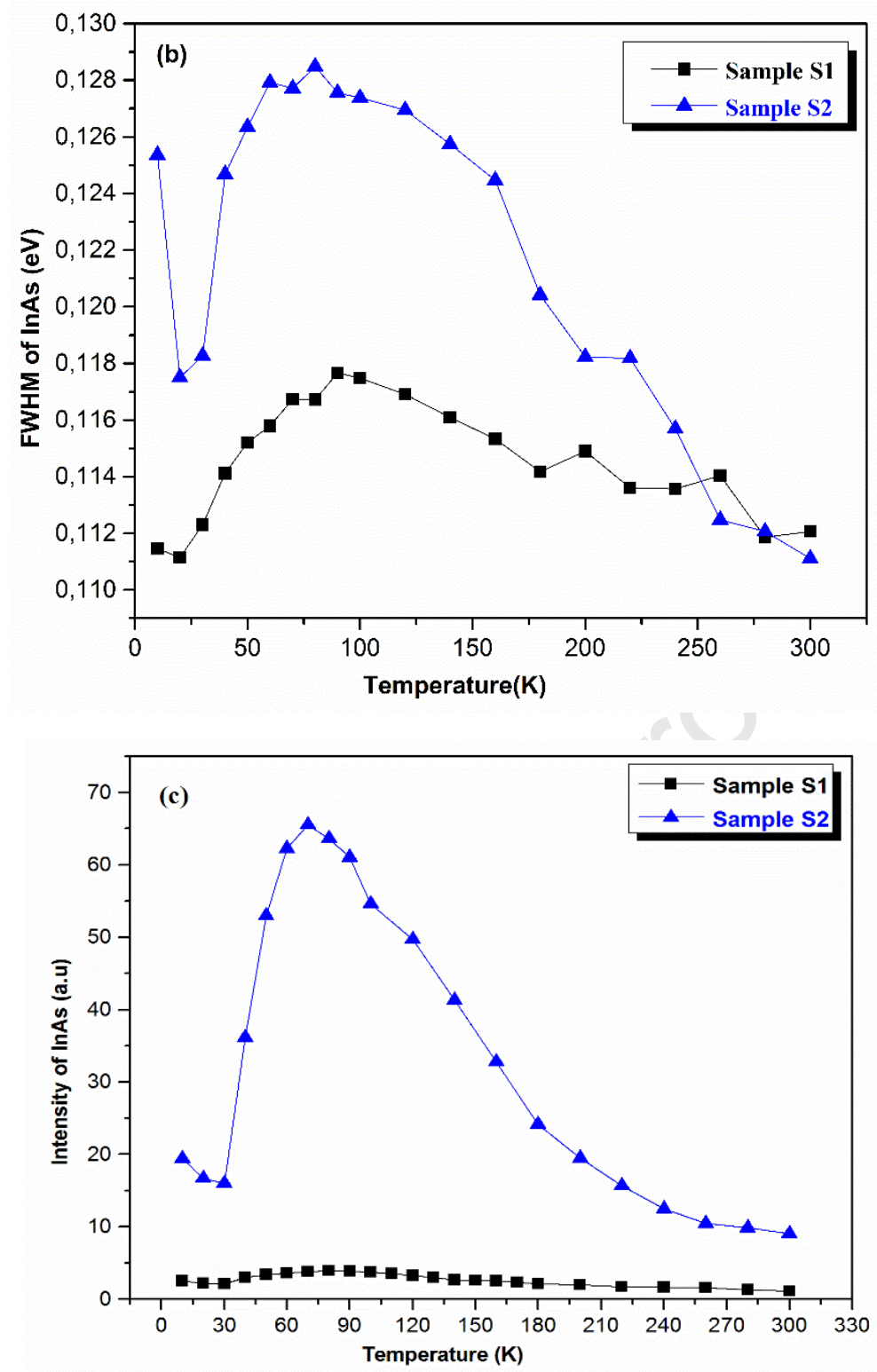

Fig.10: 

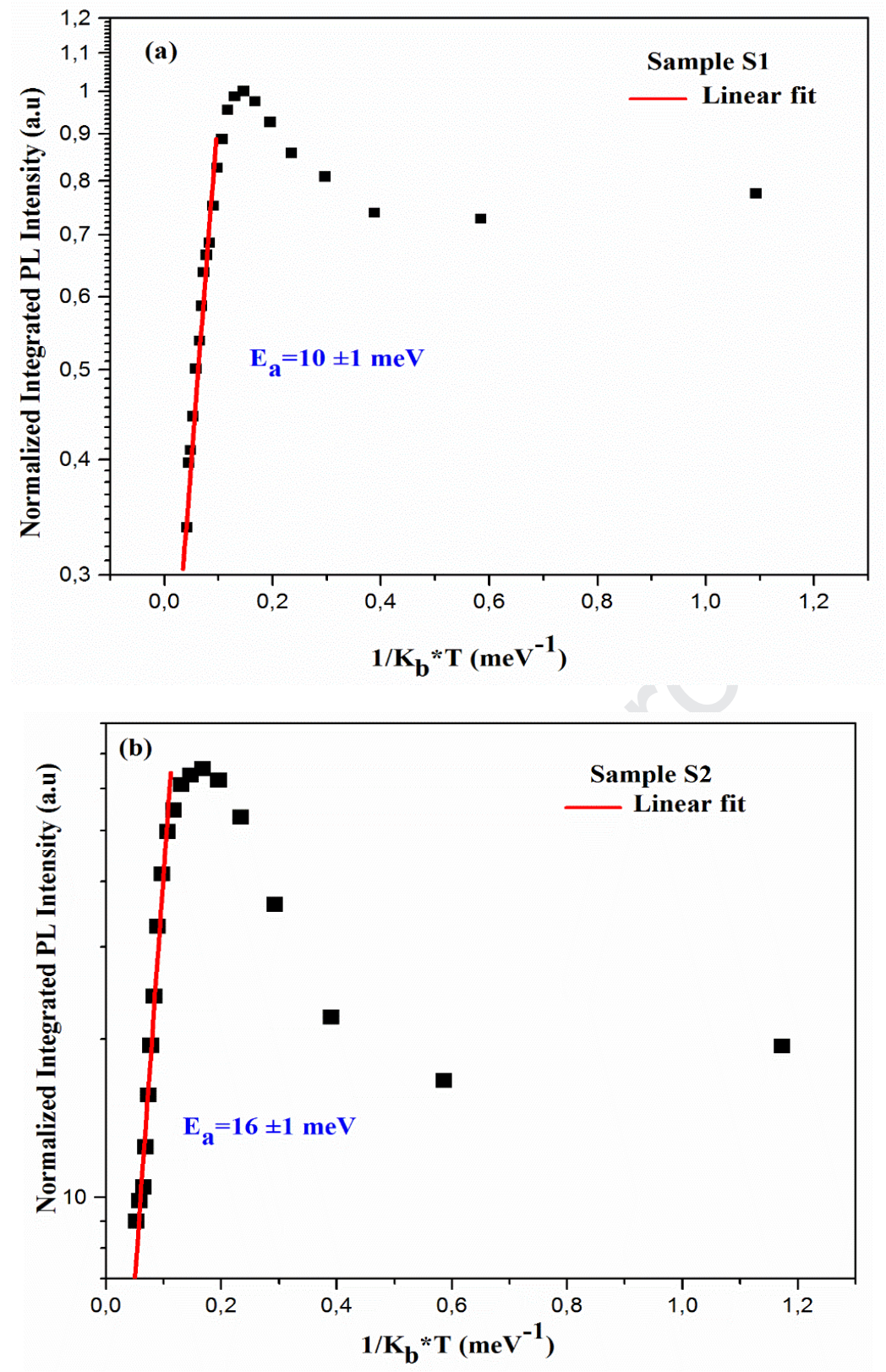


\section{Highlights}

- Influence of nitridation on optical properties in InAs QDs.

- Effect of nitridation time on QDs emission wavelength.

- Determination of nanostructure of InAs QDs on GaAs substrate after nitridation by XPS.

- S-shaped temperature dependence of photoluminescence band gap energy for nitrided InAs QDs. 
Conflict of Interest and Authorship Conformation Form

Please check the following as appropriate:

$\checkmark \quad$ All authors have participated in (a) conception and design, or analysis and interpretation of the data; (b) drafting the article or revising it critically for important intellectual content; and (c) approval of the final version.

$\checkmark \quad$ This manuscript has not been submitted to, nor is under review at, another journal or other publishing venue.

$\checkmark \quad$ The authors have no affiliation with any organization with a direct or indirect financial interest in the subject matter discussed in the manuscript

$\checkmark \quad$ The following authors have affiliations with organizations with direct or indirect financial interest in the subject matter discussed in the manuscript:

Author's name

Affiliation

\begin{tabular}{lc}
\hline Syrine Naceur & Faculté des sciences Monastir, Tunisie. \\
\hline Mohsen Choubani & Faculté des sciences Monastir, Tunisie. \\
\hline Badreddine Smiri & Faculté des sciences Monastir, Tunisie. \\
\hline Hassen Maaref & Faculté des sciences Monastir, Tunisie. \\
\hline Guillaume Monier & Institut Pascal, Université Clermont Auvergne, France. \\
\hline Christine Robert-Goumet & Institut Pascal, Université Clermont Auvergne, France. \\
\hline Larbi Sfaxi & Faculté des sciences Monastir, Tunisie. \\
\hline Bernard Gruzza & Institut Pascal, Université Clermont Auvergne, France. \\
\hline Ridha Mghaieth & Faculté des sciences Monastir, Tunisie. \\
\hline
\end{tabular}

